\title{
U.S. INFLATION AND ASSET RETURNS AROUND BUSINESS CYCLE TURNING POINTS
}

\author{
Sandip Mukherji, Howard University, Washington, DC, USA
}

dx.doi.org/10.18374/JIFS-13-3.11

\begin{abstract}
This study documents abnormally high inflation and Treasury bill returns, and low returns on long-term corporate bonds, in the 6-month period before recessions. Large and small company stocks do not anticipate recessions, suffering large losses in the first 6 months of recessions. Government and corporate bonds have abnormally high returns, anticipating expansions, in the quarter before they begin. Large company stocks anticipate expansions two months before they begin, but most of their abnormally high returns are in the first 3 months of expansions. Small company stocks do not anticipate expansions but provide abnormally high returns in the first 6 months of expansions.
\end{abstract}

Keywords: Financial Asset Returns, Business Cycles, Turning Points 